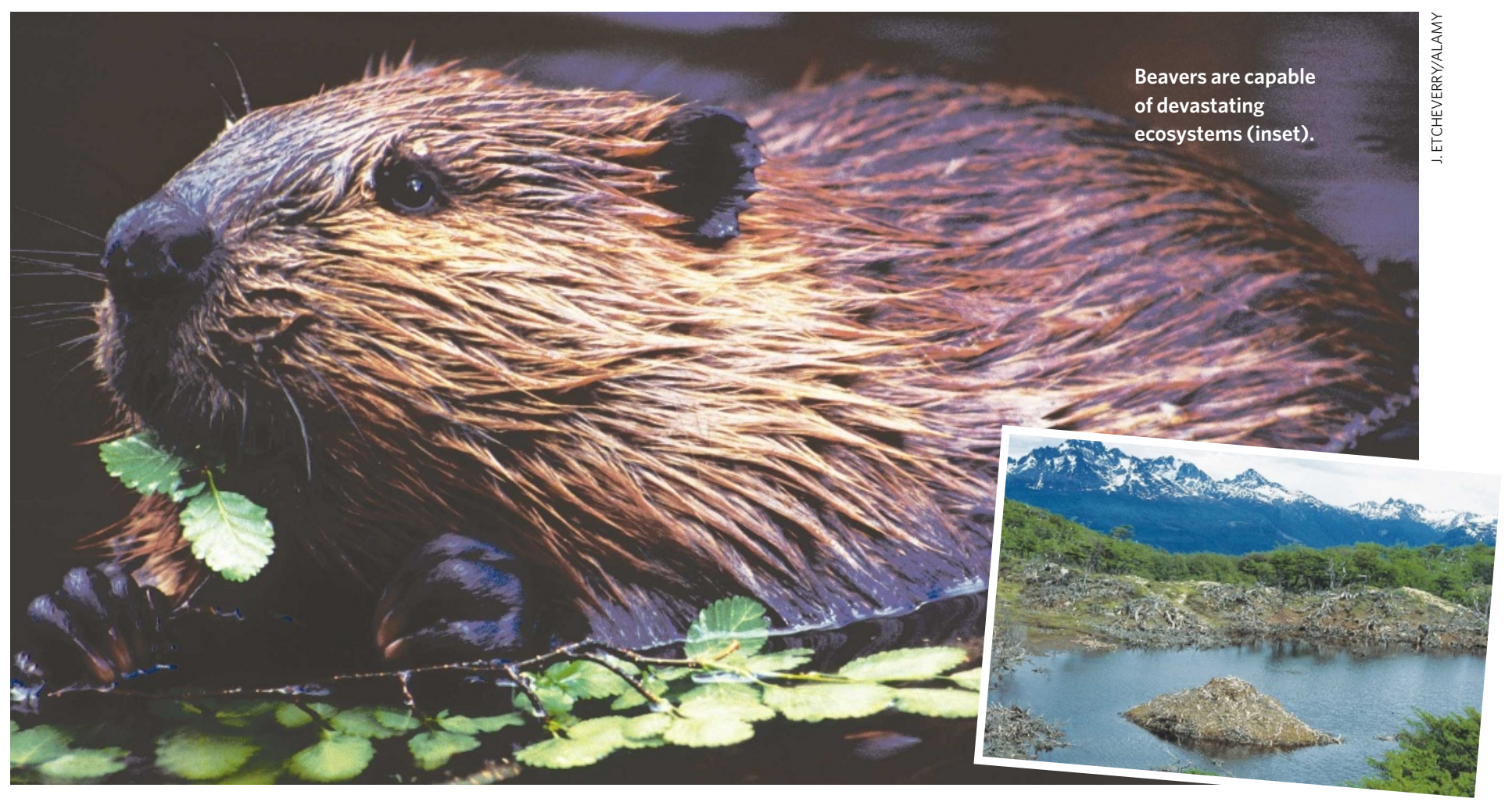
Tierra del Fuego: the beavers must die

Industrious, shy herbivores they may be, but the beavers of the Tierra del Fuego archipelago on the southern tip of South America are such a menace that scientists are planning the largest eradication project ever attempted.

In the 1940s, 50 North American beavers (Castor canadensis) were introduced to the area by the Argentine government to help start a fur industry - their numbers have now swelled to an estimated 100,000 . The aquatic rodents, which have thrived in the absence of native predators, have invaded roughly 16 million hectares of unique, indigenous forest, leaving a swath of destruction "that is absolutely stunning - it looks like bulldozers steamed through", according to ecologist Josh Donlan, director of Advanced Conservation Strategies, a non-profit organization based in Driggs, Idaho.

Although North American trees have evolved with beavers and many are able to grow back from their roots, South American trees, such as beeches, simply die when the animals gnaw them down. The dams the beavers make turn stream areas into stagnant bogs, leaving a huge impact on aquatic life, says ecologist Christopher Anderson of the Institute of Ecology and Biodiversity in Santiago, Chile. When these ponds drain out, the muddy areas become meadows that then invite exotic species. "The change in the forested portion of this biome is the largest landscape-level alteration in the Holocene - that is, approximately 10,000 years," Anderson says.

The Argentine and Chilean governments are now reviewing a feasibility study on a total eradication of these beavers, which was undertaken
by an international team including Donlan. It would be an eradication Donlan. It would be an eradication
over the largest area ever attempted "by an order of magnitude", Donlan says. Beaver-control projects, such as killing traps, are now being ramped up in a bid to test eradication methods.

\section{The dam busters}

One priority is preventing the beavers from going north - a few beavers have already been spotted on mainland Chile. To save these southernmost forests, the beavers "must be totally eradicated", says forest engineer Guillermo Martínez Pastur at the Austral Center for Scientific Investigation in Ushuaia, Argentina. But Pastur believes such an eradication "is impossible, or is of extremely high cost" because the area is extraordinarily rugged and remote.

Still, Donlan thinks it is feasible. "We've made huge progress over the past five years in removing invasive mammals from islands," he says, citing the recent eradication of some 140,000 goats from more than 500,000 hectares in the Galapagos Islands. The most likely scenario would be to go in with trappers and dogs using helicopters and boats, and adapting techniques from beaver control in the United States and Canada, Donlan says. "We'll have to move in on the beavers in a rolling front, going from watershed to watershed to remove them, with a massive monitoring programme behind it to make sure they have all been eradicated."

Anderson, who reviewed the feasibility study, also thinks eradication will be possible. "The beavers only live near the water, so you don't have to go over the whole landscape," he explains. "But you have to make sure you eradicate them all - if you have even two beavers, they could repopulate the whole archipelago."

On the opposite side of the globe, a reintroduction programme is scheduled for next year. The European beaver is to be released into Scotland where it has been extinct for 400 years, environment minister Michael Russell announced last month. "Other parts of Europe, with a similar landscape to Scotland, have reintroduced beavers and evidence shows that they can have positive ecological benefits, such as creating and maintaining a habitat hospitable to other species," he told reporters.

Charles Choi 